\title{
Design of Energy Efficient ZigBee Module
}

\author{
Odgerel Ayurzana and Sugir Tsagaanchuluun \\ Department of Electronics, Mongolian University of Science and Technology, Ulaanbaatar, Mongolia
}

\begin{abstract}
Main goal of this study was to develop an energy efficient ZigBee wireless module. The MG2455-F48 RF SoC chip was used for developing the ZigBee wireless module. This chip includes a $2.4 \mathrm{GHz}$ RF part and an 8051 family microcontroller. ZigBee modules are powered by a battery because it has to be movable. Energy saving of the ZigBee module has been one of important issues because its battery life time is limited. Nowadays many energy efficient software algorithms have been developed for ZigBee modules, which are used in data transmission between nodes. A node means a ZigBee module. In order to save energy in the ZigBee module, software algorithm was not used in this study, but we used the hardware technique. The microcontroller of ZigBee controls power of the sensors which connected on the ZigBee module. Sensors are active only when they need to transmit data and in other case the module switches to the power down mode and save energy.
\end{abstract}

Key words: Sensors, power down mode, battery, node.

\section{Introduction}

Nowadays most of electronics systems have been shifting from wired to wireless technology. There are many technological and economic advantages in wireless technology. The RF, Bluetooth, UWF and ZigBee, short range wireless communication protocols and standards have been developed and used these days. However, the ZigBee is widely used throughout the world.

ZigBee is a combination of two words such as Zigzag and Bee. The bees sound like zigzag and collect nectar through the flowers. Each flower represents one ZigBee node. Data transmission's way, distance and direction mean flying way, distance between flowers and direction of the bees.

ZigBee technology is designed to meet compliance of compliant with IEEE 802.15.4 standard and it has to be inexpensive, energy efficient, and small physical dimensions of wireless nodes [1]. Also, its network topologies can be Star $(1: 1)$, Cluster tree (1: n), Mesh (1: $n$ ). Data communication protocol is very simple, only 50 Kbytes and the maximum number of nodes in

Corresponding author: Odgerel Ayurzana, Ph.D., research fields: sensor networking, embedded systems and applications, signal processing. the network is 65,536 [2]. A node means a ZigBee module. ZigBee's standard protocol versions have been developed named as ZigBee 2006, 2007 and PRO. All those protocols have been still developed until today [3]. The data rate of MG2455-F48 chip that is used in this module is $250 \mathrm{Kbps} \sim 1 \mathrm{Mbps}$. There are three types of ZigBee modules.

(1) ZigBee Coordinator - ZC

(2) ZigBee Router - ZR

(3) ZigBee End Device - ZED

The $\mathrm{ZC}$ is a general coordinator of network. There is the unique $\mathrm{ZC}$ in the network. $\mathrm{ZR}$ routes data from module to module and is used when network expands. ZED transmits data of the attached sensors to data center through ZR and ZC. Batteries are used as a main power source of the ZigBee modules. Thus, the power saving mechanism of ZigBee module is a very important issue because of limited battery working time.

In ZigBee technology, the communication protocols are used for energy saving of module these days. Especially, if a network topology is mesh or cluster, it needs efficient algorithm to transmit data between nodes for saving battery life time. MAC-I, MAC-II, Flooding, Gossip, LEACH [4-6] are routing protocols that are developed and used for the above mentioned 
purpose.

The chip MG2455-F48 that is used for data transmission is an SoC (system on chip) which includes two blocks, $2.4 \mathrm{GHz}$ RF and embedded 8051 microcontroller blocks. Three kinds of power down modes have in a chip. The chip has 96 Kbytes of program memory, battery management unit and temperature sensor. User application software can be compiled using a popular C-language compiler Keil ${ }^{\mathrm{TM}}$ compiler.

Data transmission distance of the ZigBee module is $100 \mathrm{~m} \sim 1,000 \mathrm{~m}$ it is depended on the antenna types, external case and sizes. In our experiment where dipole antennas look at each other (open side), the distance was 1,000 meters. In the same environment, we replaced the antennas with chip antenna and the distance decreased to 150 meters. In our case, the chip antennas were used in the experiment.

MCU manages power supply of sensors which are used to measure physical parameters such as temperature, humidity, solar, air pollution using power switch chip. Sensors are active only when they need to transmit data and other case they switch to the battery saving mode.

\section{Design and Solution of ZigBee Module}

ZigBee module was designed with the MG2455-F48 SoC RF chip that is developed by the Radio pulse Company in South Korea. The chip has integrated 8051 family microcontroller.

Fig. 1 shows inside structure of the ZigBee module. Amotech chip antenna was used at the module. Also Vistro Cell's TEKCELL 3.6 V, 2,400 mAh battery and MIC94060 power management chip were chosen. MIC94060 chip controls power of the sensors. The ZC is connected to an information center computer and powered as the computer. ZR and ZED use their own battery sources and transmit their data to the ZC. As shown in Fig. 2, we used one ZC and four ZEDs for experiment. Although hardware of the ZR, ZC and ZED's is the exactly same, software configuration defines them either working as ZR, ZC or ZED.

Fig. 2 shows system diagram of ZigBee modules. There can be 65,536 numbers of the ZED and ZR in one network. There are two prerequisite to communicate modules to each other. First, all modules have to be configured in the same band. Second, the given address of each module must be unique. If those two conditions are met, the modules are ready to join in a group and change information.

\section{Working Principle of ZigBee Module}

According to the applications and sensor types, there is a mode that all sensors are always on. But in this mode there is no way to save power consumption. For saving energy consumption, power supply of sensors needs to be switched by $\mathrm{I} / \mathrm{O}$ port of the ZigBee chip. In regular time, ZigBee chip wakes up for switching on sensors power source and transmits sensors data to the $\mathrm{ZC}$, then goes to sleep mode (power down). A Power source is off when module goes to sleep mode.

Fig. 3 shows the developed ZigBee wireless module.

There are two ways to manage sensors power.

(1) To source sensors power directly from ZigBee

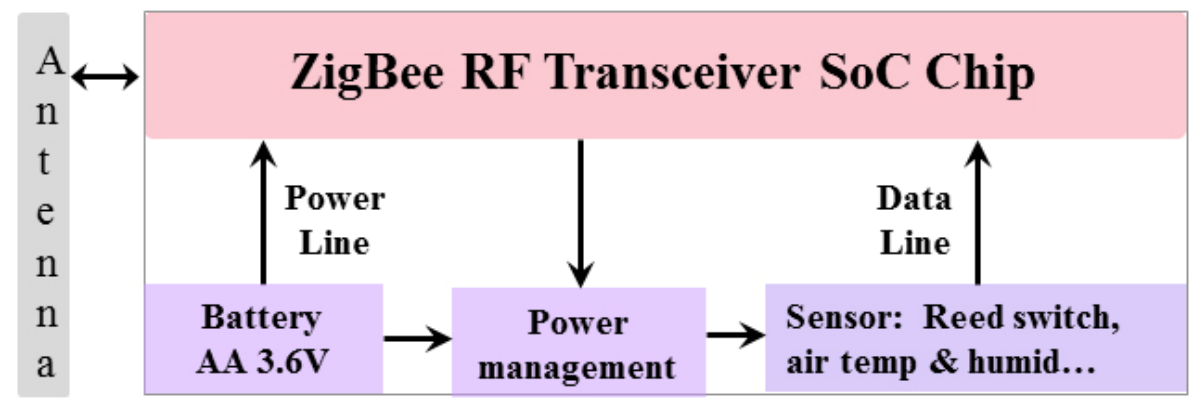

Fig. 1 Structure of a ZigBee module. 


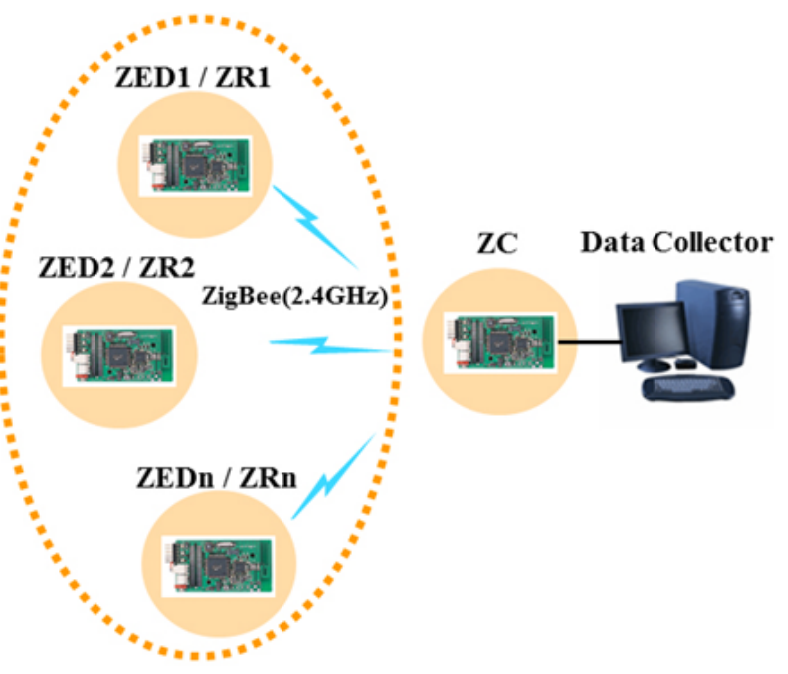

Fig. 2 System diagram.

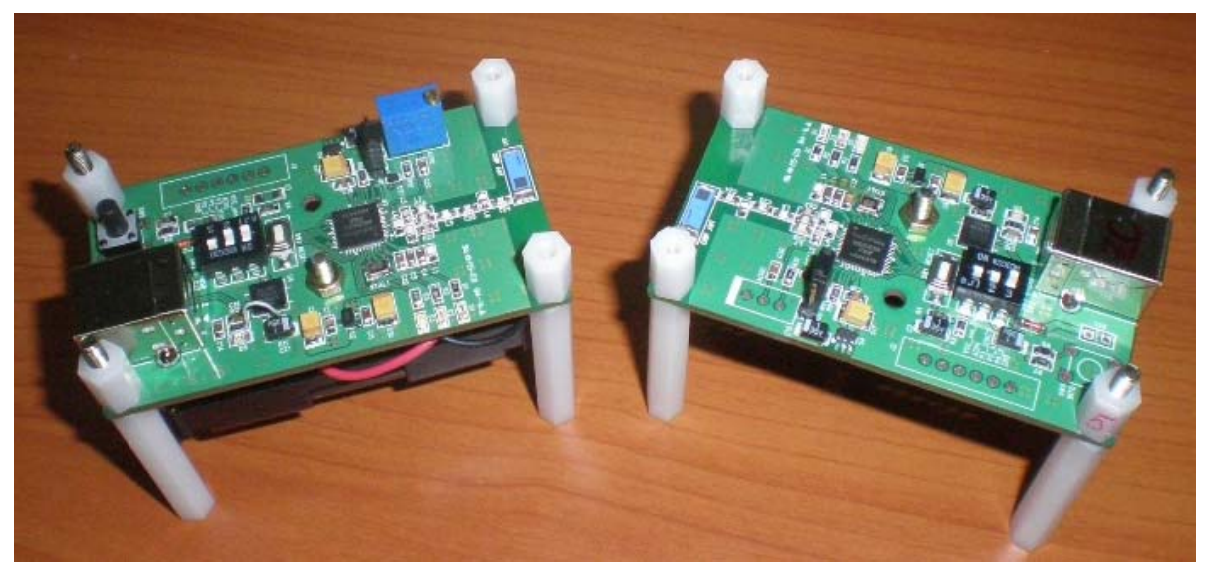

Fig. 3 Developed ZigBee module.

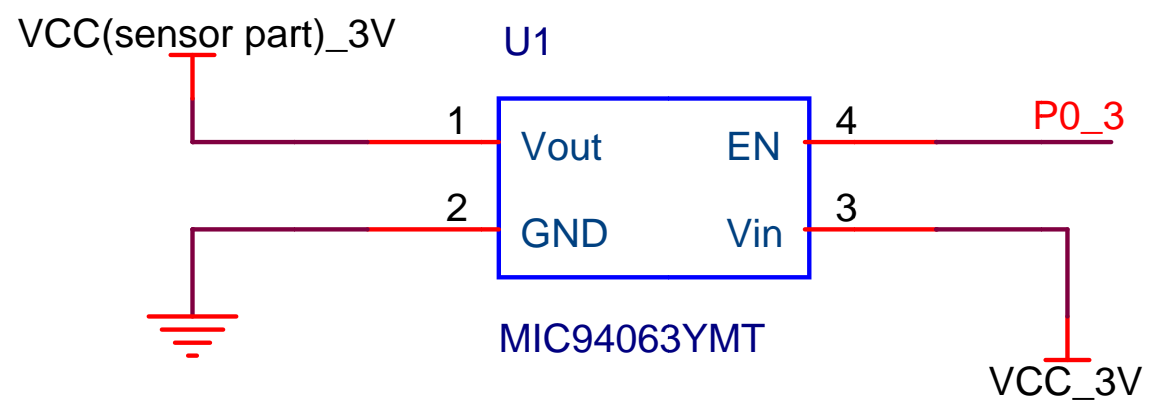

Fig. 4 Control circuit of sensor power.

chip's I/O (3 V, $15 \mathrm{~mA})$ port. It's suitable for simple On/Off sensors such as reed switch.

(2) To use special power switch chip.

In this study, second method was used. Power source of the sensors was controlled by port pin P0_3 of the ZigBee chip.

Fig. 4 shows power management chip of sensor. As mentioned above, ZigBee chip MG2455-F48 has three types of power down modes. Power down modes and power control of sensors were combined in this study for saving energy of the module.

$\mathrm{ZC}$ can connect with $\mathrm{ZR} / \mathrm{ZED}$ via two ways for changing data.

(1) Add wake up time to the ZC's data protocol for 
waking up ZR/ZED.

(2) $Z R / Z E D$ wake up periodically for sending its data.Then go to power down mode.

Table 1 shows the power modes of the MG2455-F48 chip. Table 1 considers versus current consumption at the modes and states of chip's internal peripherals.

\section{Experiment and Results}

Reed switch, photo, air temperature and humidity sensors were connected to the ZigBee module and did experiment using three power down modes. These sensors do not need to be alive always. Table 2 shows experiment result where Tx power was $8 \mathrm{dBm}$ and 0 $\mathrm{dBm}$ using power down modes. Total packet size was 127 bytes (control bytes $120+$ data bytes 7 ).

We calculated all active loads including regulator, reset switch, power switch, external interrupt switch when doing experiments. Battery life time was estimated using by data of Table 2. There were working conditions and parameters of the sensor module:

- MG2455-F48 RF Chip

- $\mathrm{Temp}=25{ }^{\circ} \mathrm{C}$

- $\mathrm{Vdd}=3.0 \mathrm{~V}$

- Core Voltage $=1.5 \mathrm{~V}$

- Clock $=16 \mathrm{MHz}$

$$
\begin{gathered}
I_{A C C}=T_{A T}[\%]^{*} I_{A C}+T_{S T}[\%]^{*} I_{S C} \\
T_{B L T}=\frac{B_{C A P}}{I_{A C C}}
\end{gathered}
$$

$I_{A C C}$ : Average Consumption Current

$T_{A T}:$ Active Time

$I_{A C}:$ Active Current

$T_{S T}$ : Sleep Time

$I_{S C}:$ Sleep Current

$T_{B L T}$ : Battery Life Time

$B_{C A P}:$ Battery Capacity

$I_{A C C}$ : Average Consumption Current

Table 3 shows parameters used in battery life time estimation of ZigBee chip.

Table 4 shows battery life time which are estimated from Table 3 and Eqs. (1) and (2).

\begin{tabular}{|c|c|c|c|c|}
\hline Power Mode & PM0 & PM1 & PM2 & PM3 \\
\hline AVREG & On & Off & Off & Off \\
\hline DVREG & On & On & Off & Off \\
\hline Main OSC & On & Off & Off & Off \\
\hline Sleep Timer & On & On & On & Off \\
\hline Wake-Up Sources & - & $\begin{array}{l}\text { HW Reset, Sleep Timer INT, } \\
\text { Ext INT }\end{array}$ & $\begin{array}{l}\text { HW Reset, Sleep Timer INT, } \\
\text { Ext INT }\end{array}$ & HW Reset, Ext INT \\
\hline Current Consumption & Normal & $25 \mathrm{uA}$ & $2 \mathrm{uA}$ & $<1 \mathrm{uA}$ \\
\hline
\end{tabular}

Table 1 Power down modes of MG2455-F48 chip.

Table 2 Result of power down modes.

\begin{tabular}{lllll}
\hline Tx Power & No PD + Tx Current & Mode 1 & Mode 2 & Mode 3 \\
\hline$+8 \mathrm{dBm}$ & $50.3 \mathrm{~mA}$ & $50.6 \mathrm{uA}$ & $47.3 \mathrm{uA}$ & $45.8 \mathrm{uA}$ \\
$0 \mathrm{dBm}$ & $44 \mathrm{~mA}$ & $50.6 \mathrm{uA}$ & $47.3 \mathrm{uA}$ & $45.8 \mathrm{uA}$ \\
\hline
\end{tabular}

Table 3 Parameters of battery life time estimation.

\begin{tabular}{ll}
\hline Battery Life Time Calculation (SB-AA11 Model) \\
\hline Battery Capacity & $2,400 \mathrm{~mA} / \mathrm{h} * 90 \%=2,160 \mathrm{~mA} / \mathrm{h}$ \\
Active Time & $1 \%(10 \mathrm{~ms}, 1 \mathrm{sec}$ period) \\
Active Current & $45 \mathrm{mAh}(\mathrm{MG} 2455,+8 \mathrm{dBm}$, with Active MCU: $4.5 \mathrm{~mA})$ \\
Sleep Time & $99 \%(990 \mathrm{~ms}, 1 \mathrm{sec}$ period) \\
& $50.6 \mathrm{uA}($ Mode 1$)$ \\
Sleep Current & $47.3 \mathrm{uA}$ (Mode 2) \\
& $45.8 \mathrm{uA}$ (Mode 3) \\
\hline
\end{tabular}


Table 4 Estimation of battery life time.

\begin{tabular}{lll}
\hline Transmission frequency (per day) & Saving Current & Battery Life Time \\
\hline $\begin{array}{l}86400 \text { times } \\
\text { (Every one sec) }\end{array}$ & $\begin{array}{l}50.6 \mathrm{uA} \\
\text { (Mode 1) }\end{array}$ & 180 Days \\
(Every 1 hour) & & 4.9 Years \\
\hline
\end{tabular}

As shown in Table 4, it can be said that in power down mode 1, where ZigBee module transmits its data 24 times a day or transmits its data every hour, battery life time is approximately 4.8 years. Apparently, in mode 2, 3 it is longer than mode 1. Also, it's important to consider battery's discharging when it's working and being saved. If sensors have to be always on according to its applications and types, life time of battery is proportionally dependent on power consumption of sensors.

\section{Conclusions}

Energy efficient ZigBee module with the MG2455 SoC was implemented and developed. Chip antenna was used instead of dipole antenna, because module size has to be small and suitable for installing in any place. However, the reliable distance was up to 150 meters and it was enough for this application. Reed switch, photo, air temperature and humidity sensors were connected to module and these sensors' supply voltage were controlled by ZigBee chip. Main power down mechanism of ZigBee module is to switch on supply voltage of sensors when it transmits its sensors value and switch off again power supply of sensors after transmission.

Also, battery $(3.6 \mathrm{~V}, 2,400 \mathrm{mAh})$ life time was estimated while MG2455 RF chip worked in power down modes. Battery life time was 4.9 years using power down mode 1 when RF chip transmits sensors' data every one hour. If sensors were chosen for suitable application, this module can use various types of wireless short range communication.

\section{Acknowledgment}

This work was done by financially supporting from ADB (Asian Development Bank) project no. 2015120740, project title of "To Develop Energy Efficient ZigBee Wireless Module for Agriculture".

\section{References}

[1] Sinem Coleri Ergen. 1995. "ZigBee/IEEE 802.15.4 Summary.” Sep 10, 2004. Wilhelm, J., and Gunther, W., Contact Materials for Reed Switches.

[2] ZigBee Alliance. 2004. Network Specification Version 1.0, Dec.

[3] NXP, 2012. "ZigBee PRO Stack User Guide."

[4] Vamsi, K. etc. 2002. "Optimal Flooding Protocol for Routing in Ad-hoc Networks." Presented at the IEEE Wireless Communication and Networking Conference.

[5] Haas, Z., Halpern, J., and Li, L. 2002. "Gossip Based Ad Hoc Routing." Presented at the IEEE Infocom Conference.

[6] Harshavardhan, S., and Krishnendu, C. 2005. "Location-Aided Flooding: An Energy-Efficient Data Dissemination Protocol for Wireless Sensor Networks." IEEE Transactions on Computers. 